\title{
NOVEL RADIATION SOURCES USING RELATIVISTIC ELECTRONS
}

\author{
From Infrared To X-Rays
}


World Scientific Series on Synchrotron Radiation Techniques and Applications

\section{Editors-in-Charge:}

D. H. Bilderback (CHESS, Cornell University, USA)

K. O. Hodgson (Dept of Chemistry and SSRL, Stanford University, USA)

M. P. Kiskinova (Sincrotrone Trieste, Italy)

R. Rosei (Sincrotrone Trieste, Italy)

\section{Published}

Vol. 1 Synchrotron Radiation Sources - A Primer H. Winick

Vol. 2 X-ray Absorption Fine Structure (XAFS) for Catalysts \& Surfaces ed. Y. Iwasawa

Vol. 3 Compact Synchrotron Light Sources E. Weihreter

Vol. 4 Novel Radiation Sources Using Relativistic Electrons P. Rullhusen, X. Artru \& P. Dhez

Forthcoming

Vol. 5 Synchrotron Radiation Theory \& Its Development V. A. Bordovitsyn

Photoelectron Spectroscopy of Solids and Surfaces K. C. Prince

Insertion Devices for Synchrotron Radiation F. Ciocci, G. Dattoli \& A. Renieri

X-ray Microscopy ed. G. R. Morrison

Medical Applications of Synchrotron Radiation eds. Al Thompson, B. Thomlinson \& M. Ando

Synchrotron Radiation Studies of Non-Crystalline Biology Systems J. Bordas \& A. Svensson 


\section{NOVEL RADIATION SOURCES USING RELATIVISTIC ELECTRONS From Infrared To X-Rays}

\section{P. Rullhusen}

European Commission, Joint Research Centre, Institute for Reference Materials and Measurements, Geel, Belgium

\section{Artru}

Institut de Physique Nucléaire de Lyon, IN2P3-CNRS, Université Claude Bernard, Lyon, France

P. Dhez

LURE, Université Paris-Sud, Orsay, France 


\section{Published by}

World Scientific Publishing Co. Pte. Ltd.

P O Box 128, Farrer Road, Singapore 912805

USA office: Suite 1B, 1060 Main Street, River Edge, NJ 07661

UK office: 57 Shelton Street, Covent Garden, London WC2H 9HE

\section{British Library Cataloguing-in-Publication Data}

A catalogue record for this book is available from the British Library.

\section{NOVEL RADIATION SOURCES USING RELATIVISTIC ELECTRONS; FROM INFRARED TO X-RAYS}

Copyright $\odot 1998$ by World Scientific Publishing Co. Pte. Ltd.

All rights reserved. This book, or parts thereof, may not be reproduced in any form or by any means, electronic or mechanical, including photocopying, recording or any information storage and retrieval system now known or to be invented, without written permission from the Publisher.

For photocopying of material in this volume, please pay a copying fee through the Copyright Clearance Center, Inc., 222 Rosewood Drive, Danvers, MA 01923, USA. In this case permission to photocopy is not required from the publisher.

ISBN 981-02-3050-8

Printed in Singapore. 


\section{PREFACE}

In 1895 W.C.Röntgen discovered the penetrating electromagnetic radiation called "X-rays" and in the past 100 years since their discovery they have proven to be an invaluable tool for research and applications in several very different fields. Most of these applications are related to radiography or characterization of materials and although significant technological progress has been achieved in improving the $\mathrm{X}$-ray tubes, they still work today on basically the same principle as at Röntgen's time.

In the seventies, synchrotron light sources became available for research and applications of radiation in a broad energy range, from the infrared to soft X-rays. In the early times, the deviation magnets of synchrotrons and storage rings designed for particle physics research were used in parasitic mode. Very soon the advantage of the high brilliance obtainable in synchrotron radiation became evident and presently most of the industrialized countries have built, or have in project, specially devoted synchrotron light facilities. For this purpose, modern storage rings are equipped with special insertion devices, called undulators and wigglers, which allow to increase the brilliance by several orders of magnitude. In all these devices, the basic phenomenon used to produce $\mathrm{X}$-rays is the interaction of relativistic particles with static magnetic fields. Although the efficiency for generating radiation by interactions with macroscopic fields is not very high, the recirculation of the electrons results in a very high effective current and nowadays undulator radiation from third-generation synchrotron rings is the brightest $\mathrm{X}$-ray source available.

At present, much effort is invested in getting $\mathrm{X}$-ray sources having beam qualities comparable to those of a laser. Free-electron lasers are the first approach using synchrotrons and linear accelerators, although short wavelengths are difficult to obtain. A different scheme based on population inversion in hot plasmas has been demonstrated about 10 years ago and most promising results have been obtained using intense short-pulsed laser beams focused on solid targets to produce plasma columns of a few centimeters length.

The novel X-ray sources described in the present book differ from the above radiative sources in many aspects. Electrons from conventional linear accelerators or microtrons of the order of $10-100 \mathrm{MeV}$ can be used, and in some 
cases (e.g., for the Smith-Purcell effect) even lower energies are advantageous. Different mechanisms will be discussed, producing radiation of very different characteristics. Therefore, for possible applications of these radiation sources, the most convenient technique has to be chosen in each case very carefully. As we will see, the basic principles of most of the effects described in this book are well known for quite some time. The radiation sources under consideration are therefore not that "novel" as the title might suggest. Routinely applications of these physical principles, however, have not yet been undertaken. Only in recent years a growing community of research laboratories started investigating in detail the feasibility of these effects as practical radiation sources, therefore justifying the emphasis on this innovative aspect.

The purpose of our book is to give a description of the state of the art in theoretical an experimental work achieved in this field. Obviously, in a small textbook like this it is not possible to give credits to all the vast amount of work carried out over the years at many different places. We have tried to summarize in a clear and comprehensible way the basic physical aspects needed to understand the phenomena, and to provide the interested reader with sufficient literature to be able to follow the development in more detail. In the theoretical description we try to give a unified view of all the effects, underlining their common properties. Not all the experimental work could be mentioned, but we have tried to include the most recent developments and to quote the most relevant papers where references to further work can be found. In many cases we took advantage of review articles and textbooks published in specialized areas.

The unified point of view of these radiation sources is a side effect of a cooperative work achieved on a soft X-ray transition radiation source by the three authors. Coming from different fields like nuclear physics, theoretical particle physics and synchrotron light research, we have profited from our complementary points of view. We would be happy if our book would encourage the discussion in this new area, giving the non-specialized researcher a basic understanding of the field while being of value for the specialist as a reference to developments in neighbouring fields. With some restrictions the book could also be interesting for students with basic knowledge of electromagnetic waves and generally interested in radiative effects obtained with relativistic electrons. 


\section{TABLE OF CONTENTS}

Preface

1. Introduction

1.1 The first century of X-rays 1

1.2 From plasma sources to X-UV lasers 9

1.3 From synchrotron radiation to free-electron-lasers 21

$\begin{array}{lll}1.4 & \text { The novel radiation sources } & 31\end{array}$

2. Radiation by Relativistic Electrons

2.1 Classification of the emission mechanisms 37

$\begin{array}{lll}2.2 & \text { Basic formalism } & 40\end{array}$

2.3 Characteristic parameters 46

2.4 Quantum effects $\quad 49$

2.5 Resonance phenomena in periodic structures 51

2.6 The Weizsäcker-Williams method of quasireal photons $\quad 55$

2.7 Classical sum rules 63

Appendix $\quad 65$

3. Synchrotron Radiation, Undulators, Free-Electron Lasers

$\begin{array}{lll}3.1 & \text { Synchrotron radiation } & 71\end{array}$

3.2 Wigglers and undulators $\quad 73$

$\begin{array}{lll}3.3 & \text { Free-electron lasers } & 81\end{array}$

4. Compton Scattering of Laser Light

$\begin{array}{lll}4.1 & \text { Introduction } & 89\end{array}$

\begin{tabular}{ll}
4.2 & Relativistic kinematics \\
\hline
\end{tabular}

4.3 Back-scattering of laser light $\quad 94$

4.4 Compton scattering at $90^{\circ} \quad 95$

5. Coherent Bremsstrahlung

$\begin{array}{llr}5.1 & \text { Introduction } & 99\end{array}$

5.2 Coherent bremsstrahlung in Born approximation 101

5.3 Validity of the Born approximation 110 
6. Channeling Radiation

6.1 Introduction 113

6.2 Planar channeling $\quad 114$

6.3 Band structure calculations 121

6.4 Axial channeling 122

6.5 Summary

7. Transition Radiation

$\begin{array}{lll}7.1 & \text { Introduction } & 127\end{array}$

$\begin{array}{lll}7.2 & \text { Transition radiation at a boundary } & 128\end{array}$

7.3 X-ray transition radiation from a thin foil 131

$\begin{array}{lll}\text { 7.4 X-ray transition radiation from a stack of foils } & 134\end{array}$

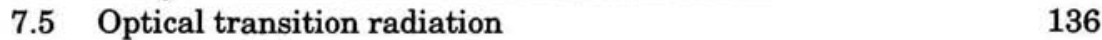

$\begin{array}{lll}7.6 & \text { Summary } & 140\end{array}$

8. Parametric X-Rays

8.1 Introduction

143

8.2 Bragg diffraction of virtual photons 143

$\begin{array}{lll}8.3 & \text { Kinematical approach } & 147\end{array}$

8.4 Dynamical theory 154

8.5 Corrections to the spectral-angular distribution 157

9. Smith-Purcell Effect

9.1 Introduction

9.2 General formalism 162

9.3 Solutions of the grating problem 166

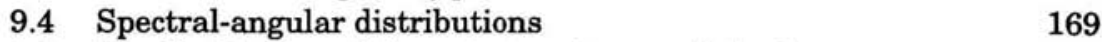

9.5 The Smith-Purcell free-electron-laser and the inverse 175 Smith-Purcell effect

10. Photon beam characteristics

10.1 Generalities

10.2 Qualitative properties of the novel X-ray sources 186

10.3 Quantitative comparison of radiation sources 192

$\begin{array}{ll}10.4 \text { Conclusion } & 197\end{array}$

Index 